\title{
Multi-level modelling of the factors that influence the participation of disabled rural individuals in social medical insurance in China
}

\author{
Ju Huang, Xi-Long Pan ${ }^{*}$ and Ang Li
}

\begin{abstract}
Background: The Second China National Sample Survey on Disability in 2006 showed that the participation rate of disabled Chinese rural individuals in social medical insurance participation was less than $30 \%$. However, there has been limited number of studies on the influencing factors, especially contextual factors, affecting their participation in social medical insurance. Therefore, this study aimed to analyze the factors influencing the participation of disabled rural individuals in social medical insurance, including contextual factors.
\end{abstract}

Methods: Based on data derived from the Second China National Sample Survey on Disability, chi-square test and two-level logistic regression model were used to analyze the influencing factors.

Results: The results showed that the disabled rural individuals in the New Rural Cooperative Medical System pilot counties who lived in communities with rehabilitation stations or with higher per capita income of villagers were more likely to participate in the social medical insurance. Meanwhile, those employed, with less severe disability degree or with less severe barriers in participation in society were more likely to participate in the social medical insurance.

Conclusions: Contextual factors including economic and policy contexts were important factors influencing their participation in social medical insurance before 2006 in China. Unemployment, severer disability degree and social isolation might also prevent them from gaining equal access to social medical insurance.

Keywords: Multilevel modeling, Influencing factor, Rural disabled persons, Social medical insurance

\section{Background}

Disability $^{(a)}$ is a serious issue in the whole world drawing increasing attention. Some international organizations and countries have introduced programs or laws to protect their rights. World Program of Action Concerning Disabled Persons [1] approved by the United Nations in 1982 and Convention of the United Nations on the Rights of Persons with Disabilities [2] passed in 2006 stressed on the full participation and equal rights of the disabled persons. In China, the Law of the People's Republic of China on the Protection of Disabled Persons [3] enacted in 1990 and was revised in 2008. These are the current laws protecting their legal rights in China. In spite of this, the medical security of disabled persons

\footnotetext{
*Correspondence: xilongpan11@163.com

Department of Health Policy and Management, School of Public Health, Peking University Health Science Center, 38 Xueyuan RoadHaidian District, Beijing, China
}

\section{Biomed Central

(c) 2013 Huang et al.; licensee BioMed Central Ltd. This is an Open Access article distributed under the terms of the Creative Commons Attribution License (http://creativecommons.org/licenses/by/2.0), which permits unrestricted use, distribution, and reproduction in any medium, provided the original work is properly cited. was largely restrained, thus the new Medical Reform of China [4] emphasized on their medical security.

There are 650 million disabled individuals all over the world, accounting for $10 \%$ of the world's total population [5]. According to the Second China National Sample Survey on Disability (SCNSSD), by April 1, 2006, the total number of the disabled in China was 82.96 million, accounting for $6 \%$ of the national population. Among them, the majority ( 62.25 million, $75 \%$ of all the disabled population) were in the rural areas [6]. The total number of households with disabled persons was 70.50 million, accounting for $18 \%$ of the national households [6]. However, despite the large population of this vulnerable group, only $32 \%$ of them were covered by social medical insurance schemes in 2006 [7] and the coverage was generally lower in the rural areas (average of $28 \%$ ) as compared to the urban areas. The coverage also varied in different provinces ranging from under $10 \%$ to $79 \%[8,9]$. 
Disabilities may cause diseases that might lead to poverty and poverty might in return cause diseases that reinforce disabilities. Therefore, a vicious circle shadows the life of some disabled individuals [10]. In fact, $42 \%$ of the absolutely poverty-stricken people are disabled [11]. The results from the Sample Survey on one thousandth of disabled individuals in Beijing in 2005 showed that the average expenditure on medical rehabilitation of the disabled individuals was 4,108 Yuan, accounting for $81 \%$ of their average annual income, but $176 \%$ of the annual income of the disabled in rural areas [12]. The survey also revealed that $60-70 \%$ of the rural disabled received no medical rehabilitation [13].

Studies on social medical insurance of the disabled are quite few in China, especially before 2006 when the lack of survey data made it impossible to carry out comprehensive studies on social medical insurance of disabled individuals. Based on the data of the SCNSSD, some domestic scholars carried out studies on medical security [14-18]. However, these studies had certain limitations on the theory and method design. Yintong [17] reported that the policy context might affect the disabled persons' social medical insurance participation. However, due to the inclusion of only urban disabled persons and the limitations mentioned above, it was difficult to determine the influence of policy context on disabled persons' participation in social medical insurance. Zhoumi [18] tried to explore the factors, which might influence disabled persons' purchase of social medical insurance; however, it was just restricted to one province. Thus, whether policy context or other factors have influence on rural disabled persons' participation in social medical insurance is unknown. At the same time, scholars have focused their attention on the barriers caused by disability rather than by the social medical insurance system and the policy context. This study utilized scientific and practical methods to explore the influences on rural disabled persons' participation in social medical insurance. We hypothesized that contextual factors, including policy and economic factors could influence rural disabled persons' participation in social medical insurance. Furthermore, we hypothesized that with the increasing severity of disability degree, contextual factors might have increasing influences on rural disabled persons' participation in social medical insurance.

\section{Methods}

\section{Setting and sampling}

This study was based on the data derived from SCNSSD. In order to understand the latest situation of the disabled individuals so as to help formulate development plans and relevant regulations, China carried out the SCNSSD in 2006. There are many definitions for "disabled person/person with disability". The SCNSSD and this study adopted the concept of disabled persons in Law of the People's Republic of China on the Protection of Disabled Persons. Based on these, the disabled person refers to people who have lost all or part of the ability to engage in certain activities in the normal way as a result of certain tissue or function loss or psychological, physiological or anatomical abnormality. This definition also includes people with visual, hearing, speech, physical and mental disabilities along with mental retardation or multiple disabilities [3].

The SCNSSD was a population-based, nationally representative survey that was conducted in 2006 in China. The target population was households that were sampled from 31 provinces, autonomous regions and municipalities in China (Figure 1). A stratified, multiphase and cluster probability sampling design was used to randomly sample participants at four levels including county, town, village and community. The sample size in each level was based on the proportion of population to the province. Four towns were selected in each county, two villages in each town and one community in each village. Finally, the SCNSSD sampled a total of about $2,500,000$ people from 5,964 communities of 2,980 towns in 734 counties.

This study was based on a part of the results from the SCNSSD database that was provided by China Disabled Persons Federation. According to the objective of this study, disabled persons above the age of 18 in Chinese rural areas were included. A total of 114,485 individuals were studied. This study was funded by China Disabled Persons' Federation (2010\&YB004).

\section{Data collection}

In order to get the actual number of households and population, the investigators entered into the survey communities ahead of time. The "Survey Reference Book" was formulated based on the actual situation. Onsite registration consisted of household survey and disability assessment. As for the household survey, the households were investigated under the guidance of "Survey Reference Book" using "Survey Questionnaire for Household". As for the disability assessment, doctors of various specialties combined the stationary and household surveys to assess the disability on an individual basis. Finally, the completed survey questionnaires were reviewed comprehensively by investigators and doctors.

\section{Quality of data}

\section{Representativeness}

The comparison of the age structure, sex ratio and other demographic indicators of the SCNSSD data in 2006 with the data from the 1\% Population Sample Survey in 2005 showed that the sample had a good representativeness. 


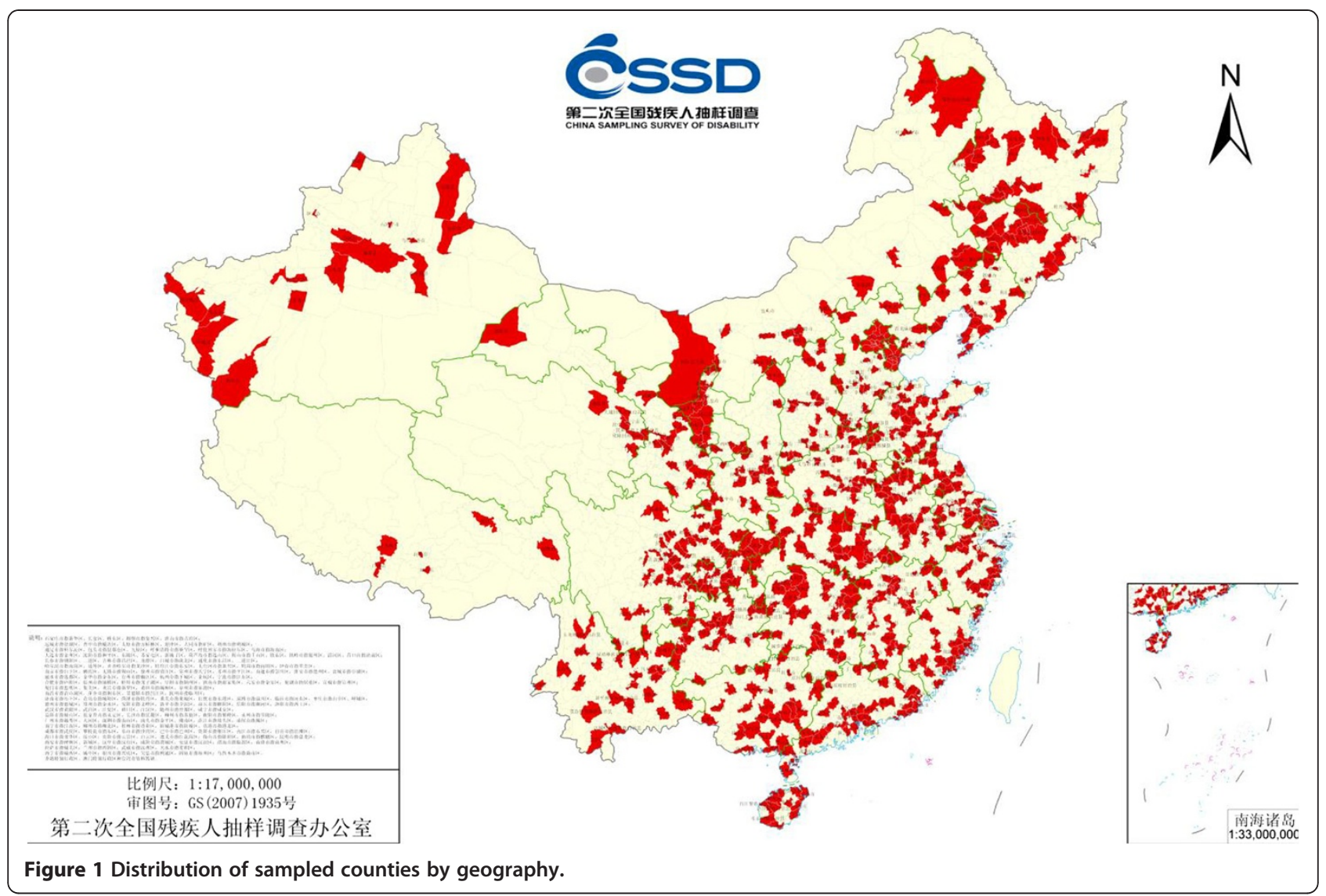

\section{Integrity}

The post-survey quality check showed that the omission rate was $1.31 \%$ for the registered population and $1.12 \%$ for the disabled population. This was an indication of a high integrity.

\section{Reliability}

Under the 95\% and 90\% confidence levels, the allowable errors for the proportion of surveyed disabled population to the national population were $0.97 \%$ o and $0.80 \%$ respectively. According to some experimental data provided by the United Nation (UN) experts, the data with a relative error of less than $10 \%$ was considered reliable. Based on this, the SCNSSD data was reliable.

\section{Accuracy}

The Whipple's index was 96.00 for the males and 96.10 for the females, which were very close to 100 . Furthermore, the Myer's index was 1.55, which was less than 5, indicating that the SCNSSD data was accurate.

In summary, the SCNSSD data had a high quality.

\section{Variables description}

\section{Outcome measure (Dependent variable)}

The dependent variable was Participation in Social Medical Insurance, which was binary $(1=$ Yes; $0=$ No).

\section{Individual-level variables (Independent variables)}

The individual-level variables included demographic indicators (gender, age, educational level and marital status), economic status indicator (Per Capita Household Income (PCHI)) and disability status indicators (disability type, disability degree and participation in society).

Gender was a dummy variable, coded as 1 and 2, representing male and female, respectively. Age was a continuous variable, representing participant's age at the time of the baseline interview. Educational level was a dummy variable, coded as 1,2 and 3 , representing college or above, primary, high and technical secondary school and primary school and below, respectively. Marital status was a dummy variable, coded as 1 and 2, representing in marriage and not in marriage, respectively.

Employment was a dummy variable, coded as 1 and 2, representing employed and unemployed, respectively. 
PCHI was based on the information gathered from the $1 \%$ of the census (2005), which indicated a poverty level of 683 Yuan [19]. The average per capita household income in our sample was 2,281 Yuan. Therefore, our analysis used three income levels, coded as 1, 2 and 3, representing 683 or less, $684-2,300$, and 2,301 or more, respectively.

Disability degree was a dummy variable, coded as 1,2 , 3 and 4, representing grade-1 (most severe), grade-2, grade- 3 and grade- 4 (least severe), respectively. Participation in society was a dummy variable, coded as 1,2 and 3, representing none/mild barriers, moderate barriers and severe barriers, respectively.

\section{Community-level variables (Independent variables)}

Community-level variables were indicators of the communities where the disabled lived, including an economic status indicator (Per Capita Income of the Villagers in 2005 (PCIV)), a policy indicator (New Rural Cooperative Medical System Pilot County (NPC)) and other contextual indicators (Special Committees for the Disabled (SCD) and rehabilitation stations).

The average PCIV in our sample was 2,800 Yuan. Therefore, in our analysis we used three income levels, coded as 1, 2 and 3, representing 683 or less, $684-2,800$ and 2,801 or more, respectively. NPC was a dummy variable, coded as 1 and 2, representing NPC and non-NPC, respectively. SCD was a dummy variable, coded as 1 and 2 , representing with SCD and without SCD, respectively. Rehabilitation station was a dummy variable, coded as 1 and 2, representing with rehabilitation stations and without rehabilitation stations, respectively.

More than 2,300 Yuan, grade-4, severe barriers, more than 2,801 Yuan, non-NPC, without SCD and without rehabilitation station served as the reference.

\section{Statistical analysis}

The methods of calculating frequencies and averages were used to describe the independent variables. The $x^{2}$-test was used to examine the independent associations between rural disabled persons' social medical insurance participation rate and each independent variable.

Because of the hierarchical structure of the data and the discrete outcome, multilevel logistic regression analysis, a type of the Generalized Linear Mixed Model [20], was used to assess the association between independent variables and rural disabled persons' participation rate. Multilevel logistic regression model is an extension of fixed effect logistic regression, incorporating random effects into the model in order to deal with the intraclass correlation coefficient (ICC) that arises in multilevel data. This study established a Two-Level Logistic Regression Model, with the individual (including outcome measure and individual variables) as level-1 and the community as level-2. The hierarchical structure and variable distribution are shown in Figure 2.

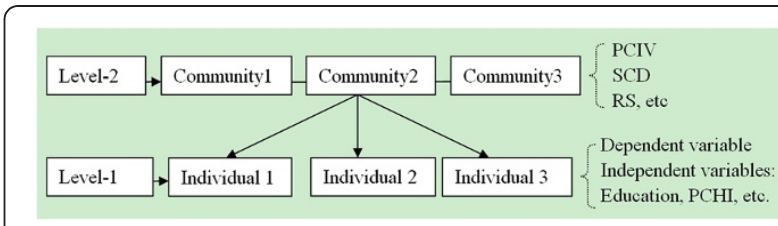

Figure 2 Hierarchical structure of the two-level model and distribution of relevant variables.

In step-1, a null model was developed to assess the within-group homogeneity. The results of running an empty model showed a significant between-group variation in the mean outcome measure (ICC $=0.8264$, $\left.\sigma^{2} \mu_{0}=-2.72, p<0.0001\right)$. An ICC of 0.8264 was very large and indicated that $82.64 \%$ of the total variation in the mean outcome measure was caused by variation between the survey sites. The combined model was $\log \left(\frac{p_{i j}}{1-p_{i j}}\right)=\gamma_{00}+u_{0 j}$, where $p_{i j}$ was the probability of rural disabled persons' participation in social medical insurance and $u_{0} j$ was the random variation in the level-1 intercept across groups (survey sites in this study), which represents the deviations of the $j^{\text {th }}$ group's mean logit from the overall mean logit.

As such, in step-2, contextual variables explaining the between-site variation are explored without adjusting for individual characteristics. Thus, the combined multilevel logit model was as follows:

$$
\begin{aligned}
\log \left(\frac{p_{i j}}{1-p_{i j}}\right) & =\gamma_{00}+\gamma_{01} P C I V+\gamma_{02} N P C+\gamma_{03} S C D \\
& +\gamma_{04} R S+u_{0 j}
\end{aligned}
$$

In step-3, a model was tested by adding level- 1 explanatory variables into the random intercept and slop logit model. The multilevel logit model was as follows:

$$
\begin{aligned}
\log \left(\frac{p_{i j}}{1-p_{i j}}\right) & =\beta_{0 j}+\beta_{0 j} D D_{i j}+\beta_{2} \text { Gender }_{i j} \\
& +\beta_{3} \text { Employment }_{i j}+\beta_{4} P C H I_{i j} \\
& +\beta_{5} P S_{i j} \beta_{0 j}=\gamma_{00}+\gamma_{01} P C I V_{j} \\
& +\gamma_{02} N P C_{j}+\gamma_{03} S C D_{j}+\gamma_{04} R S_{j} \\
& +u_{0 j} \beta_{1 j}=\gamma_{10}+\gamma_{11} P C I V_{j}+u_{1 j}
\end{aligned}
$$

The combined model was:

$$
\begin{aligned}
\log \left(\frac{p_{i j}}{1-p_{i j}}\right) & =\gamma_{00}+\gamma_{01} P C I V_{j}+\gamma_{02} N P C_{j}+\gamma_{03} S C D_{j} \\
& +\gamma_{04} R S_{j}+\gamma_{10} D D_{i j}+\gamma_{11} P C I V_{j} * \mathrm{DD}_{i j} \\
& +\beta_{2} \text { Gender }_{i j}+\beta_{3} \text { Employment }_{i j} \\
& +\beta_{4} \mathrm{PCHI}_{i j}+\beta_{5} \mathrm{PS}_{i j}+\left(\mathrm{u}_{0 \mathrm{j}}+\mathrm{u}_{1 j} * \mathrm{DD}_{i j}\right)
\end{aligned}
$$

The glimmixed and nlmixed procedures of the SAS9.13 were used for statistical analysis [20]. 


\section{Results}

\section{Descriptive analysis}

In this study, the total number of the disabled individuals with rural residence over the age of 18 was 114,485 . Of those, 57,296 were male $(50 \%)$ and 57,189 were female (50\%). As such, the other individual-level and community-level characteristics of the participants are shown in Table 1.

\section{Univariate analysis}

Among the rural disabled persons investigated in 2006, only 32,374 participated in social medical insurance, accounting for $28 \%$. Compared with the disabled rural individuals who were unemployed, with lower PCHI, with more severe disability degree or with more severe barriers in participation in society respectively, those employed with higher PCHI, with less severe disability degree or with less severe barriers in participation in society had significantly higher social medical insurance participation rates $(\mathrm{p}<0.001)$. As for the communitylevel variables, the rural disabled persons in the area with rehabilitation stations, with SCD, in NPC or with a higher PCIV had significantly higher social medical insurance participation rates than those in the area without rehabilitation stations, without SCD, in non-NPC or with lower PCIV $(\mathrm{p}<0.001$, Table 1$)$

\section{Multilevel analysis}

The analysis of the models verified the influence of policy and economic factors on rural disabled persons' participation in social medical insurance and further showed the relevance between rural disabled persons' disability degree and their participation in social medical insurance. However, the interaction between the policy and economic factors and the disability degree was not statistically significant. Therefore, it was uncertain whether the influence of contextual factors on rural disabled persons' participation in social medical insurance would vary with the disability degree. The detailed steps were as follows.

A null model was developed to assess the withingroup homogeneity, which turned out to be quite large (See Statistical analysis). The community-level variables were added to model 1 . The results showed that the odds of participating in social medical insurance of rural disabled persons in the area with RS, in NPC and with higher PCIV were higher, with statistical significance. However, SCD did not influence rural disabled persons' participation in social medical insurance. The individuallevel variables including disability degree, participation in society, PCHI and employment were added to model 2. All the results were statistically significant with a $-2 * \log$ Likelihood (LL) of $658,390.6$. Therefore, the odds of participating in social medical insurance of rural disabled persons with more severe disability degree, more severe barriers in participation in society, lower PCHI or no job were lower.

The individual-level background variables such as gender and age were added to model 3 as covariates. The results showed that the age was not statistically significant, thus it was removed from the analysis. Finally, the -2LL of model 3 was 658,366.3. The difference in -2LL (likelihood ratio $(\mathrm{LR})=24.3, \mathrm{df}=2, \mathrm{p}<0.0001$ ) between model 3 and 2 indicated that the fit of model 3 improved over model 2 with an acceptable statistical significance. In order to discuss how NRCMS pilot policy mediated the effects of disability degree on rural disabled persons' social medical insurance participation, the cross-level interaction between NPC and disability degree was added to model 4 . The results showed that the interaction was not statistically significant with a $-2 \mathrm{LL}$ of $658,387.4$ for model 4 . The difference in -2LL ( $\mathrm{LR}=-21.1, \mathrm{df}=2, \mathrm{p}<0.0001$ ) between model 4 and 3 indicated that the fit of model 3 was better. Meanwhile, the cross-level interaction between disability degree, PCHI, participation in society, employment and other community-level variables were also tested but showed no statistical significance. Therefore, model 3 was chosen in the end.

Based on the results gathered from the assessment of model 3, the contextual factors including policy and economic contexts had important influence on rural disabled persons' participation in social medical insurance in China. A statistically significant relationship was found in 3 community-level variables. More specifically, rural disabled persons in NPC had higher odds of participating in social medical insurance as compared to those in non-NPC (odds ratio [OR]: 3.34; 95\% confidence interval [CI]: 2.62-4.25). Furthermore, rural disabled persons in the area with rehabilitation stations had higher odds of participating in social medical insurance than those without rehabilitation stations (OR: 1.87; 95\% CI: 1.49-2.36). Rural disabled persons with higher PCIV were more likely to participate in social medical insurance. The rural disabled persons with PCIV of less than 683 Yuan or even 1,684 to 2,800 Yuan had lower odds of participation in social medical insurance than those with more than 2,801 Yuan (OR: 0.36; 95\% CI: 0.28-0.46 and OR: 0.45; 95\% CI: 0.37-0.55, Table 2).

Other important influencing factors were employment, disability degree and participation in society. Rural disabled persons who were employed had higher odds of participating in social medical insurance as compared to those unemployed (OR: 1.11; 95\% CI: 1.06-1.16). As for the disability degree, rural disabled persons with more severe disability were less likely to participate in social medical insurance. Rural disabled persons with a grade-1, 2 or 3 disability had lower odds of participating in social medical insurance as compared to those with a 
Table 1 Descriptive statistics of rural disabled persons' independent variables and social medical insurance participation rate and significance of univariate analysis

$\begin{array}{ccc}\text { Variable } & \text { Sample size } & \text { Social medical } \\ \text { and proportion } & \text { insurance } \\ \mathbf{N}(\%) & \text { participation } \\ & \text { rate (\%) }\end{array}$

Participation in social medical insurance

Yes

No

$32374(28)$

$82111(72)$

Level 2 characteristic $\mathrm{N}=\mathbf{5 2 2 0}$

Rehabilitation Stations**

Yes

No

Special Committees for the Disabled**

$$
\text { Yes }
$$

No

$N P C^{* *}$

Yes

No

Per Capita Income of Villagers in 2005**

683 or less

684-2800

2301 or more

Gender*

$$
\text { Male }
$$

Female

Educational Level**

College or Above

Primary, High and Technical

Secondary School

Primary School and Below

Employment**

Yes

No

Marital Status**

In Marriage

Not in Marriage

Per Capita Household Income(PCHI)**

683 or less

684-2300

2301 or more

Disability Degree**

grade-1 (most severe)

grade-2

grade-3

grade-4 (least severe)
1014 (19)

$4206(81)$

$2369(45)$

$2851(55)$

36

Table 1 Descriptive statistics of rural disabled persons' independent variables and social medical insurance participation rate and significance of univariate analysis (Continued)

\begin{tabular}{lll}
\hline Participation in Society** & & \\
None/ Mild barriers & $51328(45)$ & 29 \\
Moderate barriers & $36343(32)$ & 29 \\
Severe barriers & $26814(23)$ & 26 \\
\hline
\end{tabular}

\section{*Significant at 0.05 ,}

**Significant at 0.001 , significance of the $x^{2}$-test, examining the independent associations between rural disabled persons' social medical insurance participation and independent variables.

(1)
medical insurance. In China, policy is the most important factor influencing the rural disabled persons' participation in social medical insurance. Our results showed that the odds of participating in social medical insurance of rural disabled persons in NPC were 3.34 times larger as compared to those in non-NPC, which also applies to the real situation.

At the end of 2003, China began to launch NRCMS pilots in part of China [21], which amounted to about $40 \%$ of the national counties (cities and districts) in 2006 [22]. The social medical insurance participation rates in various pilot studies have been on the rise since 2003 with the spread of NRCMS pilots. Wusheng county, the NPC in Sichuang province since August 2003, had a total of 1,311,000 person-times participating in social medical insurance over the past three years, of which 435,100 participated from 2003 to 2004 (participation rate $=61 \%), 371,000(51 \%)$ in 2005 and 504,900 (69\%) in 2006 [23]. Meanwhile, the low self-paid premium of NRCMS largely promoted rural disabled persons' participation in social medical insurance. In 2003, the minimum annual self-paid premium of NRCMS was only 10 Yuan while the corresponding average payment of the
medical insurance for urban workers was 271 Yuan [24].

in social medical insurance in China and unemployment.
Furthermore, severer disability degree and social isolamedical insurance for urban workers was 271 Yuan [24]. 
Table 2 Estimates and test results of model 3

\begin{tabular}{|c|c|c|c|c|}
\hline \multicolumn{5}{|c|}{ Odd ratio $(95 \% \mathrm{Cl})$} \\
\hline Variable & Model 1 & Model 2 & Model 3 & Model 4 \\
\hline \multicolumn{5}{|l|}{ Level-2 } \\
\hline \multicolumn{5}{|c|}{ Special Committees for Disability } \\
\hline Yes & $1.00(0.82,1.21)$ & $0.98(0.81,1.20)$ & & \\
\hline No & 1.0 & 1.0 & & \\
\hline \multicolumn{5}{|l|}{ Rehabilitation Station } \\
\hline Yes & $1.91(1.49,2.45)^{* *}$ & $1.88(1.47,2.41) * *$ & $1.87(1.49,2.36)^{* *}$ & $1.87(1.49,2.36)^{* *}$ \\
\hline No & 1.0 & 1.0 & 1.0 & 1.0 \\
\hline \multicolumn{5}{|l|}{ NPC } \\
\hline Yes & $3.36(2.64,4.27)^{* *}$ & $3.34(2.62,4.25) * *$ & $3.34(2.62,4.25)^{* *}$ & $3.38(2.65,4.31) * *$ \\
\hline No & 1.0 & 1.0 & 1.0 & 1.0 \\
\hline \multicolumn{5}{|c|}{ Per Capita Income of Villagers in 2005} \\
\hline 683 or less & $0.37(0.29,0.48)^{* *}$ & $0.36(0.28,0.46) * *$ & $0.36(0.28,0.46)^{* *}$ & $0.36(0.28,0.46)^{* *}$ \\
\hline $684-2800$ & $0.43(0.35,0.52)^{* *}$ & $0.45(0.37,0.55) * *$ & $0.45(0.37,0.55)^{* *}$ & $0.45(0.37,0.55) * *$ \\
\hline 2301 or more & 1.0 & 1.0 & 1.0 & 1.0 \\
\hline \multicolumn{5}{|l|}{ Level-1 } \\
\hline Intercept & $0.15(0.12,0.18)^{* *}$ & $0.096(0.08,0.11)^{* *}$ & $0.098(0.09,0.11)^{* *}$ & $0.16(0.14,0.19)^{* *}$ \\
\hline \multicolumn{5}{|l|}{ Gender } \\
\hline Male & & & $1.07(1.02,1.11)^{* *}$ & $1.07(1.02,1.11)^{* *}$ \\
\hline Female & & & 1.0 & 1.0 \\
\hline \multicolumn{5}{|l|}{ Employment } \\
\hline Yes & & $1.12(1.07,1.18) * *$ & $1.11(1.06,1.16)^{* *}$ & $1.11(1.06,1.16)^{* *}$ \\
\hline No & & 1.0 & 1.0 & 1.0 \\
\hline \multicolumn{5}{|c|}{ Per Capita Household Income in 2005} \\
\hline 683 or less & & $0.69(0.64,0.75) * *$ & $0.68(0.63,0.74)^{* *}$ & $0.69(0.63,0.74)^{* *}$ \\
\hline $684-2300$ & & $0.84(0.80,0.88) * *$ & $0.83(0.79,0.88)^{* *}$ & $0.83(0.79,0.88)^{* *}$ \\
\hline 2301 or more & & 1.0 & 1.0 & 1.0 \\
\hline \multicolumn{5}{|l|}{ Disability Degree } \\
\hline grade-1 (most severe) & & $0.80(0.75,0.86)^{* *}$ & $0.80(0.75,0.86)^{* *}$ & $0.82(0.75,0.89) * *$ \\
\hline grade-2 & & $0.81(0.75,0.87)^{* *}$ & $0.80(0.75,0.87)^{* *}$ & $0.82(0.74,0.90)^{* *}$ \\
\hline grade-3 & & $0.82(0.78,0.86) * *$ & $0.82(0.77,0.86)^{* *}$ & $0.80(0.75,0.86)^{* *}$ \\
\hline grade-4 (least severe) & & 1.0 & 1.0 & 1.0 \\
\hline \multicolumn{5}{|l|}{ Participation in Society } \\
\hline None/ Mild barriers & & $1.10(1.02,1.18) *$ & $1.10(1.03,1.18) *$ & $1.10(1.03,1.18) *$ \\
\hline Moderate barriers & & $1.10(1.03,1.18)^{*}$ & $1.10(1.03,1.18) *$ & $1.10(1.03,1.18) *$ \\
\hline Severe barriers & & 1.0 & 1.0 & 1.0 \\
\hline
\end{tabular}

\section{Cross-Level Interactions}

social medical insurance Pilot County \& Disability Degree

Yes\& grade-1

$1.06(0.91,1.24)$

Yes\&grade-2

$1.04(0.87,1.26)$

Yes\&grade-3

$0.95(0.83,1.09)$

Yes\&grade-4

* Significant at 0.05 ,

** Significant at 0.001 , significance of the two-level logistic regression analysis, assessing the association between independent variables and rural disabled persons' social medical insurance participation. 
Therefore, the policy was the most important factor influencing rural disabled persons' participation in social medical insurance. However, there was no NRCMS related central policy specified for rural disabled persons, which might influence rural disabled persons' participation in social medical insurance, especially those with lower PCHI or more severe disability degree.

These results showed that the odds of participating in social medical insurance of rural disabled persons in the area with rehabilitation stations were 1.87 times larger than those without rehabilitation stations. In 2002, "Views on Further Strengthening Rehabilitation Work for Disabled Persons" [25] pointed out the importance of introducing rehabilitation work into the community for disabled persons by gradually providing the community and household rehabilitation services to the disabled persons in order to raise funds through multiple channels for the rehabilitation aid of poor disabled persons, to construct the rehabilitation infrastructure for disabled persons and to carry out post-rehabilitation professional and labor skills to promote education, employment and full participation in society for disabled persons. The establishment of rehabilitation stations might reflect the enforcement of rehabilitation policy. Strict enforcement of this policy can largely promote rehabilitation services, skill training, education and employment for disabled persons, which could increase the probability of their participation in social medical insurance.

These results showed that the rural disabled persons with higher PCHI or in the area with higher PCIV were more likely to participate in medical insurance. The areas with better economic status might provide more preferential policies for the rural disabled, such as lower self-paid premium and higher hospitalization reimbursement. Our results showed that the rural disabled persons in the areas with better economic status had higher initiatives to participate in social medical insurance. Although the minimum self-paid premium of NRCMS was only 10 Yuan, the rural disabled persons with low income were more likely to spend the money on consumer goods to obtain maximum utility. The satisfaction survey of NRCMS in Liaoning province showed that the farmers with a better economic status or better health status showed higher satisfaction with NRCMS [26]. Thus rural disabled persons with worse economic status or worse health status benefited less from NRCMS. Furthermore, due to the low financing level, low reimbursement rate and limited disease coverage, without corresponding preferential policies, the rural disabled with poor economic status had low initiatives to participate in social medical insurance.

The odds of participating in social medical insurance of employed rural disabled persons were 1.11 times higher than that of the unemployed. In 2006, the social medical insurance in China was mainly consisted of medical insurance for urban workers, which had already been spread all over China, and NRCMS, which only piloted in a part of China. Medical insurance for urban workers covered all the workers of townships and village enterprises. Therefore, the employed rural disabled persons were covered by medical insurance for urban workers and obtained medical security.

As for the disability degree and participation in society, rural disabled persons with more severe disability or barriers were less likely to participate in social medical insurance. The disability reduced the probability of being employed, especially for those with severe disability, thus reduced the odds of participation in social medical insurance. Also, disability and unemployment worsened the economic status and restrained their knowledge of policy due to the barriers thus reduced the odds of participation in social medical insurance. Based on these findings, we concluded that China rural disabled persons' medical security was constrained by their disabilities and social participation barriers before 2006, which might have seriously prevented them from gaining equal access to medical security.

\section{Conclusions}

The analysis above showed that contextual factors, including economic and policy contexts, were important factors influencing rural disabled persons' participation in social medical insurance before 2006 in China. Unemployment, severer disability degree and social isolation might also largely prevent them from gaining equal access to social medical insurance. Therefore, the key for disabled persons to obtain equal medical security is to develop comprehensive social medical insurance policies and a series of strategies ensuring the strict implementation. Employment and education opportunities should be created to help disabled persons get back to normal life and obtain social medical insurance. Rehabilitation services should be strengthened to help disabled persons regain or compensate functions, improve quality of life and enhance social participation. With these measures, the disabled persons' rights of equal access to medical security could be guaranteed and their human rights and social civilization could also be promoted. Just as the Convention on the Rights of Persons with Disabilities said, "to promote, protect and guarantee sufficient and equal access to all human rights and fundamental freedoms of the disabled, and promote respect for the inherent dignity of the disabled" [2].

\section{Limitations}

There were some limitations in this study. The SCNSSD in 2006 was designed to provide reference data for the disability cause, so the survey data on social medical 
insurance might have not been comprehensive and might have affected the construction of the proposed model. However, this data met the need for studying the influencing factors of social medical insurance for the disabled with high quality and can be used. Furthermore, this study had a huge data volume and multiple variables, which largely slowed the operational speed of running multilevel model and resulted in non-convergent results. Therefore, in the model operation, we tried to simplify the model to improve the operational efficiency.

\section{Endnotes}

${ }^{a}$ According to Convention on the Rights of Person with Disabilities [2], disability is an evolving concept and disability results from the interaction between persons with impairments and attitudinal and environmental barriers that hinders their full and effective participation in society on an equal basis with others. Persons with disabilities include those who have long-term physical, mental, intellectual or sensory impairments which in interaction with various barriers may hinder their full and effective participation in society on an equal basis with others. In the context of the International Classification of Functioning, Disability and Health [27], disability is an umbrella term, covering impairments, activity limitations and participation restrictions. An impairment is a problem in body function or structure; an activity limitation is a difficulty encountered by an individual in executing a task or action; while a participation restriction is a problem experienced by an individual in involvement in life situations. Thus disability is a complex phenomenon, reflecting an interaction between features of a person's body and features of the society in which he or she lives.

\section{Abbreviations}

ICC: Intraclass Correlation Coefficient; NPC: NRCMS Pilot County; NRCMS: New Rural Cooperative Medical System; PCHI: Per Capita Households Income; PCIV: Per Capita Income of the Villagers in 2005; SCD: Special Committees for the Disabled; SCNSSD: Second China National Sample Survey on Disability.

\section{Competing interests}

This study was funded by China Disabled Persons' Federation (Project Number: 2010\&YB004). In 2010, China Disabled Persons' Federation granted us an amount of funding, which was managed by Peking University Health Science Center. Since the funding was limited, it could not cover the costs of this manuscript. Therefore, the authors had to pay a proportion of the cost. The authors declared that they had no other financial competing interests.

\section{Authors' contributions}

This paper took the jointed efforts of the three authors. JH conceived of the original idea and participated in its data collection, statistical analysis and writing. XLP participated in the study design, critical revision and coordination. AL participated in the statistical analysis, writing, revision and translation. All authors read and approved the final manuscript.
}

\section{Acknowledgements}

This study was funded by China Disabled Persons' Federation (Project Number: 2010\&YB004). We would like to express our sincerest gratitude to them for their support and help. We thank them for their financial and material support. Also, thank them for allowing us to access the data and use the results in this paper. Without them, we could not complete this study.
Received: 31 August 2011 Accepted: 14 January 2013

Published: 12 February 2013

\section{References}

1. World Programme of Action Concerning Disabled Persons: [http://www.un. org/disabilities/default.asp?id=23]

2. UN Department of Economics and Social Affairs: Handbook on the Convention on the Rights of Person with Disabilities. Beijing: Huaxia Publishing House; 2008.

3. Law of the People's Republic of China on the Protection of Disabled Persons: [http://www.cdpf.org.cn/mrxx/content/2008-05/09/content_25055884.htm]

4. Liu JF: Interpretation of the new medical reform for exploring medical security of the disabled persons. Disability in China 2009, 7:52.

5. International Day of Persons with Disabilities: [http://www.who.int/ mediacentre/events/annual/day_disabilities/en/index.html]

6. Office of the Second China National Sample Survey on Disability: Handbook on the Main Data of the Second China National Sample Survey on Disability. Beijing: Huaxia Publishing House; 2007.

7. Office of the Second China National Sample Survey on Disability: Documentation of the Second China National Sample Survey on Disability. Beijing: China Statistics Press; 2007.

8. Cheng K, Zheng XY: Data Analysis of the Second China National Sample Survey on Disability. Beijing: Huaxia Publishing House; 2008.

9. Du P: Persons with Disability in China's Rural Areas and their Social Security. Beijing: Huaxia Publishing House; 2008.

10. Qi X, Li CM: Report on the social security for the disabled persons in Beijing. Population and Development 2008, 03:90-98.

11. Statistical Communiqué of the 10th Five-year Plan Outline Implementation of the Disability Cause: [http://www.cdpf.org.cn/sytj/content/2007-12/02/ content_84247_12.htm]

12. Qi X, Li CM: Study on social medical insurance for disabled persons in Beijing. Health Economics Research 2007, 2:48.

13. Tian Y: A study on social security system of Chinese countryside disabled person. Changchun: Jilin University; 2009.

14. Cheng L: Study of social security issues of China disabled persons. Jinan: Shandong Normal University; 2008.

15. Meng X: Research on the social security of the disable person in China. Changchun: Jilin University; 2008.

16. Cheng K: Analysis of social security issues of China disabled persons. Red Flag Manuscript 2006, 7:23-25.

17. Yin T: Analysis of basic medical insurance condition of urban disabled persons and its determinants in China. Beijing: Peking University; 2008.

18. Zhou M: Research on the influence factors of Gansu rural disable's state that to participate medical social insurance. Lanzhou: Lanzhou University; 2009.

19. National Bureau of Statistics of People's Republic of China: China Statistical Yearbook 2005. Beijing: China Statistics Press; 2006.

20. Wang JC, Xie HY, Jiang BF: Multilevel Models. Beijing: High Education Press; 2008.

21. Ministry of Agriculture: Ministry of Health and Ministry of Finance Views on Establishment of New Rural Cooperative Medical System. [http://www.gov.cn/ ztzl/2005-12/30/content_142875.htm]

22. Ministry of Health, National Development and Reform Commission, Ministry of Civil Affairs, Ministry of Finance, Ministry of Agriculture, State Food and Drug Administration: State Administration of Traditional Chinese Medicine Notice of Promoting Pilot Work of New Rural Cooperative Medical System. [http://www.gov.cn/gzdt/2006-01/19/content_164221.htm]

23. Guang'an Development and Reform Committee: Periodical achievements of new rural cooperative medical system pilots. Sichuan Reform 2007, 3:39-41.

24. Human Resources of the People's Republic of China and Ministry of Social Security: China Labour Statistical Yearbook. Beijing: China Statistics Press; 2004.

25. Ministry of Health, Ministry of Civil Affairs, Ministry of Finance, Ministry of Public Security, Ministry of Education: China Disabled Persons' Federation Notice of Views on Further Strengthening the Rehabilitation Work for Disabled Persons. [http://www.sdpc.gov.cn/shfz/t20070620_143353.htm]

26. Pan $X L$, Zhang $Y, X u L$, Huang J, Zhao QQ: An analysis of farmers' perception of the new cooperative medical system in Liaoning Province, China. BMC Health Serv Res 2009, 9:230.

27. Disabilities: [http://www.who.int/topics/disabilities/en/index.html]

\section{doi:10.1186/1472-6963-13-58}

Cite this article as: Huang et al:: Multi-level modelling of the factors that influence the participation of disabled rural individuals in social medical insurance in China. BMC Health Services Research 2013 13:58. 